\title{
Electronic Throttle Control System: Modeling, Identification and Model-Based Control Designs
}

\author{
Robert N. K. Loh', Witt Thanom ${ }^{1,2}$, Jan S. Pyko ${ }^{1,2}$, Anson Lee ${ }^{1,2}$ \\ ${ }^{1}$ Center for Robotics and Advanced Automation, Department of Electrical and Computer Engineering, \\ Oakland University, Rochester, USA \\ ${ }^{2}$ Electrical \& Electronic Systems Engineering, Chrysler Group LLC, Auburn Hills, USA \\ Email: tporntha@oakland.edu, loh@oakland.edu
}

Received May 19, 2013; revised June 19, 2013; accepted June 26, 2013

Copyright (C) 2013 Robert N. K. Loh et al. This is an open access article distributed under the Creative Commons Attribution License, which permits unrestricted use, distribution, and reproduction in any medium, provided the original work is properly cited.

\begin{abstract}
Electronic throttle control (ETC) system has worked its way to become a standard subsystem in most of the current automobiles as it has contributed much to the improvement of fuel economy, emissions, drivability and safety. Precision control of the subsystem, which consists of a dc motor driving a throttle plate, a pre-loaded return spring and a set of gear train to regulate airflow into the engine, seems rather straightforward and yet complex. The difficulties lie in the unknown system parameters, hard nonlinearity of the pre-loaded spring that pulls the throttle plate to its default position, and friction, among others. In this paper, we extend our previous results obtained for the modeling, unknown system parameters identification and control of a commercially available Bosch's DV-E5 ETC system. Details of modeling and parameters identification based on laboratory experiments, data analysis, and knowledge of the system are provided. The parameters identification results were verified and validated by a real-time PID control implemented with an xPC Target. A nonlinear control design was then proposed utilizing the input-output feedback linearization approach and technique. In view of a recent massive auto recalls due to the controversial uncontrollable engine accelerations, the results of this paper may inspire further research interest on the drive-by-wire technology.
\end{abstract}

Keywords: ETC System; System Identification; Nonlinear Control; Input-Output Feedback Linearization; xPC Target-Based Control System

\section{Introduction}

In the automotive industry, one of the fruitful technologies that have emerged from the increasing regulations in terms of fuel economy, emission control, drivability and safety is the drive-by-wire technology that creates the electronic throttle control (ETC) system [1,2]. The system comprises of a throttle plate equipped with a preloaded spring and is driven by an electronic-controlled dc motor to regulate airflow in the intake manifold. In modern vehicles, the engine control unit computes and maps the throttle plate's angle to many entries such as accelerator pedal position, engine speed, cruise control command, and so forth in order to achieve optimal air-fuel mixtures in the combustion chambers, thereby maximizing fuel economy and minimizing emissions. The ETC system, which responses to the prescribed reference from the engine control unit must operate with fast transient responses and precise control to regulate the throttle plate's angular position $[3,4]$.
In recent years, research in the ETC system and related areas has been very active in both academia and industry [5-20]. The research challenge lies mainly in the unknown system parameters, high nonlinearity characteristic of the throttle module caused by friction and a pre-loaded spring. In the area of modeling and identification, a series of laboratory experiments that yield the parameter values of an ETC model was presented in [5], and the complete model was verified through simulations and real-time implementation. In [6], an ETC model based on the LuGre friction model was developed. Further modifications including parameter verification based on several experiments were shown in [7]. In [8], the authors characterized the effects of transmission friction and nonlinearity of the return spring by means of computer simulations, experiments, and analytical calculations. Another topic of research by the same authors in which an automatic parameter tuning method was adopted to enhance the control system robustness was pro- 
posed in [9]. Reference [10] proposed a discrete-time piecewise affine model of the ETC system, and applied the clustering-based procedure to identify the parameters. Yet another approach based on nonlinear optimization and genetic algorithms were applied to estimate the unknown ETC system parameters in [11].

Much research has been conducted in the area of control strategies as well. Controller realizations based on proportional-integral-derivative (PID) algorithm supplemented with friction feedback/feed-forward can be found in $[8,12,13]$. In addition, a comparative study of the performance and advantages among the three controllers: a PID, Linear Quadratic Regulator (LQR), and LQR-plusIntegral controllers was addressed in [13]. A linearquadratic-Gaussian (LQG) based control was proposed in [14]. Researches that utilized the sliding mode control (SMC) technique applied to an ETC system can be found in $[11,15,16]$, and neural networks-based SMC in [17]. In [18] the development of an adaptive control scheme that guarantees speed tracking was presented. In the system integration level, the authors of [19] considered the control strategy for a vehicle with ETC and automatic transmission. They applied dynamic programming technique to optimize the transmission gear shift and throttle opening to maximize fuel economy and power demand from the driver's accelerator pedal position. In [20], the authors proposed a throttle-control algorithm that compensates two sources of delays, in the throttle response and in the manifold filling, in order to improve the engine response.

This paper enhances our previous research results in [5]. We provide in details the procedure of laboratory experiments for identifying each unknown system parameter. Data and analytical computations are also provided. A nonlinear control strategy based on the inputoutput feedback linearization approach is then investigated. The paper is organized as follows. Section 2 describes the physical components and mathematical modeling of the ETC system. Section 3 elaborates in details the identification method of each system parameter. Step-by-step tests, experiments and detailed data analysis are provided to arrive at the set of system parameters. The parameters obtained were verified and validated in Section 4. The proposed design of a model-based nonlinear controller for the ETC system is illustrated in Section 5, followed by the simulation results in Section 6 . Finally, Section 7 contains the conclusion.

\section{ETC System Modeling}

A pictorial view of a Bosch DV-E5 ETC system [21], particularly the throttle module, used in many vehicle models is shown in Figure 1. The module consists of:

- a throttle plate driven by an armature-controlled dc motor with two redundant angular position sensors;

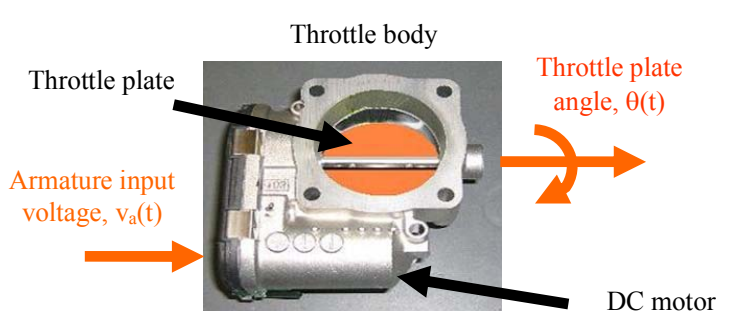

Figure 1. Pictorial view of the Bosch ETC system.

- throttle plate angle limiters acting as a mechanical stop at $90^{\circ}$ when the throttle plate is in the fully open position, and approximately $7.5^{\circ}$ in the fully closed position [12]. This small partial opening of the throttle plate provides enough air flow to allow the engine to run at its idle speed, allowing a driver to crawl a vehicle, sometimes referred to as limp home, to a safe place in the absence of throttle control full power;

- two sets of reduction gear trains with a total gear ratio of $N=20.68$ obtained by physically counting the numbers of the gear teeth;

- a return spring $K_{s}$ which ensures a safe return of the throttle plate to its closed position when no driving torque is generated by the dc motor.

A schematic representation of the ETC system of Figure $\mathbf{1}$ is displayed in Figure 2.

The mathematical model for the ETC system can be treated as a single-shaft mechanical system by transferring all the model parameters to the throttle plate shaft (load) through the gear ratio. The parameters and notations used in deriving the mathematical model of this particular ETC system are listed below:

$R_{a}$ : Resistance of the armature circuit,

$L_{a}$ : Inductance of the armature circuit,

$K_{b}$ : Back electromotive force (emf) coefficient referred to the motor side,

$\bar{K}_{b}$ : Back emf coefficient referred to the load side,

$K_{m}$ : Motor torque constant referred to the motor side,

$\bar{K}_{m}^{m}:$ Motor torque constant referred to the load side,

$J_{m}$ : Motor moment of inertia,

$J_{L}$ : Throttle plate moment of inertia,

$J_{e q}$ : Equivalent moment of inertial referred to the load side,

$B_{m}$ : Motor viscous damping coefficient,

$B_{L}$ : Throttle plate viscous damping coefficient,

$B_{e q}$ : Equivalent viscous damping coefficient referred to the load side,

$K_{s}:$ Return spring stiffness,

$T_{P L}$ : Spring pre-loaded torque,

$T_{f}$ : Frictional torque generated by the movement of the throttle plate,

$N$ : Gear ratio $\left(N=n_{L} / n_{m}=\omega_{m} / \omega_{L}>0\right)$,

$e_{b}(t)$ : Voltage produced by emf,

$\theta_{L}(t)$ : Angular position of the throttle plate, 


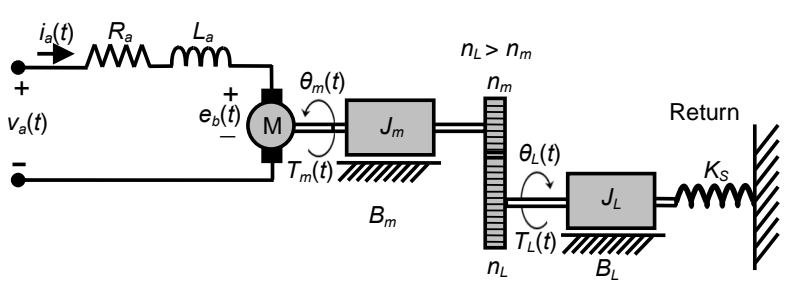

Figure 2. Schematic of the ETC system.

$\omega_{L}(t)$ : Angular velocity of the throttle plate,

$\theta_{m}(t)$ : Angular position of the motor,

$\omega_{m}(t)$ : Angular velocity of the motor,

$T_{L}(t)$ : Load torque transmitted through the reduction gear trains,

$v_{a}(t)$ : Armature voltage,

$i_{a}(t)$ : Armature current.

With reference to Figure 2, the armature circuit of the ETC system is described by

$$
L_{a} \frac{\mathrm{d} i_{a}(t)}{\mathrm{d} t}+R_{a} i_{a}(t)+K_{b} \omega_{m}(t)=v_{a}(t) .
$$

Substituting $N=\omega_{m} / \omega_{L}$ and $\bar{K}_{b}=K_{b} N$ into (1) yields

$$
L_{a} \frac{\mathrm{d} i_{a}(t)}{\mathrm{d} t}+R_{a} i_{a}(t)+\bar{K}_{b} \omega_{L}(t)=v_{a}(t) .
$$

The torque balance equation is given by

$$
J_{m} \dot{\omega}_{m}(t)+B_{m} \omega_{m}(t)+\frac{T_{L}(t)}{N}=K_{m} i_{a}(t) .
$$
by

The ETC system load torque $T_{L}(t)$ in (3) is governed

$$
\begin{aligned}
T_{L}(t)= & J_{L} \dot{\omega}_{L}(t)+B_{L} \omega_{L}(t) \\
& +K_{s} \theta_{L}(t)+T_{P L}+T_{f} \operatorname{sgn}\left(\omega_{L}\right)
\end{aligned}
$$

where $\operatorname{sgn}\left(\omega_{L}\right)$ is the signum function defined by

$$
\operatorname{sgn}\left(\omega_{L}\right)= \begin{cases}-1 & \text { if } \omega_{L}<0, \\ 0 & \text { if } \omega_{L}=0, \\ 1 & \text { if } \omega_{L}>0 .\end{cases}
$$

Combining (3) and (4) with $N=\omega_{m} / \omega_{L}$ yields

$$
\begin{aligned}
& J_{e q} \dot{\omega}_{L}(t)+B_{e q} \omega_{L}(t)+K_{s} \theta_{L}(t) \\
& +T_{P L}+T_{f} \operatorname{sgn}\left(\omega_{L}\right)=\bar{K}_{m} i_{a}(t),
\end{aligned}
$$

where $J_{e q}=\left(N^{2} J_{m}+J_{L}\right), B_{e q}=\left(N^{2} B_{m}+B_{L}\right)$, and $\bar{K}_{m}=N K_{m}^{e q}$. Equations (2) and (6), therefore, represent the ETC mathematical model referred to the load side. The immediate task now is to identify all the unknown parameters and constants: $L_{a}, R_{a}, J_{e q}, B_{e q}, \bar{K}_{b}, \bar{K}_{m}, K_{s}$, $T_{P L}$, and $T_{f}$, which are needed to facilitate the designs of the model-based ETC feedback control systems in Sections 5 and 6.

\section{System Identification}

System parameter identification is, in general, one of the most critical and difficult tasks in system modeling, analysis and synthesis. The following approaches are commonly used: 1) application of mathematical system parameters identification algorithms and techniques [22, 23]; 2) estimation based on laboratory experiments; and 3) a combination of 1) and 2). In this section, we present a series of laboratory experiments to identify the parameters of the Bosch ETC system model described in Section 2. The approach is practical and proved to be effective for the ETC system investigated. The details of each experiment are described as follows.

\subsection{Stalled Motor Resistance Test}

In this experiment, the throttle plate was held fixed at its closed position. A slowly varying dc voltage was applied to the motor terminals which, in turn, caused the motor current to increase slowly. The data of the voltage and current were captured. Since the throttle plate was locked, that is, $\omega_{L}(t)=0$, and with the fact that the armature current changed very slowly, $\mathrm{d} i_{a} / \mathrm{d} t \approx 0$, thus (2) is reduced to a simple Ohm's law

$$
R_{a} i_{a}(t)=v_{a}(t) .
$$

The plot of the armature voltage $v_{a}(t)$ and armature current $i_{a}(t)$ in (7) is shown in Figure 3. The inverse of the slope of the approximated line yields the armature resistance which reads $R_{a}=1.15 \Omega$.

\subsection{Stalled Motor Inductance Test}

The throttle plate was still held fixed at the closed position. A step voltage $V_{a}$ was applied to the stalled motor terminals. As a result, the back emf voltage $e_{b}(t)$ was zero because there was no angular velocity. Therefore, the armature circuit in (1) or (2) can be expressed as

$$
L_{a} \frac{\mathrm{d} i_{a}(t)}{\mathrm{d} t}+R_{t} i_{a}(t)=V_{a}
$$

where $R_{t}$ was the total armature circuit resistance consisting of the resistances of the armature circuit, current sensor and all the wiring in the measurement set up. The solution of the first-order differential Equation (8) with a step voltage $V_{a}$ and the initial condition $i_{a}(0)=0$ is given by

$$
i_{a}(t)=\frac{V_{a}}{R_{t}}\left(1-\mathrm{e}^{-t / \tau}\right)
$$

where $\tau=L_{a} / R_{t}$ is the electrical time-constant of the dc motor. Figure 4 shows the oscilloscope-captured waveforms of the resulting motor voltage and current.

At steady state, after $3 \mathrm{~ms}$, the total resistance was approximately $R_{t}=V_{a} / i_{a}=1.59 / 1.05 \approx 1.5 \Omega$. The time $t$ 


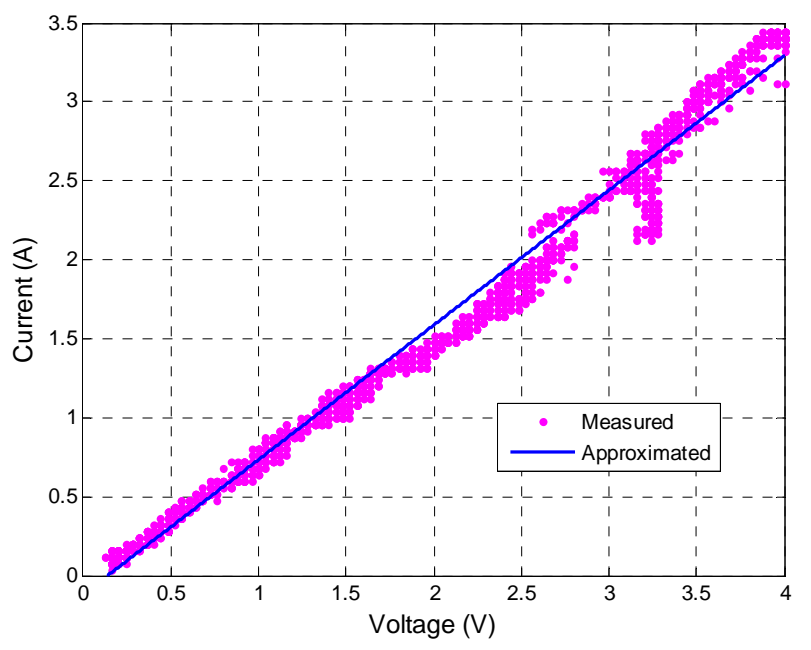

Figure 3. Stalled motor voltage versus current.

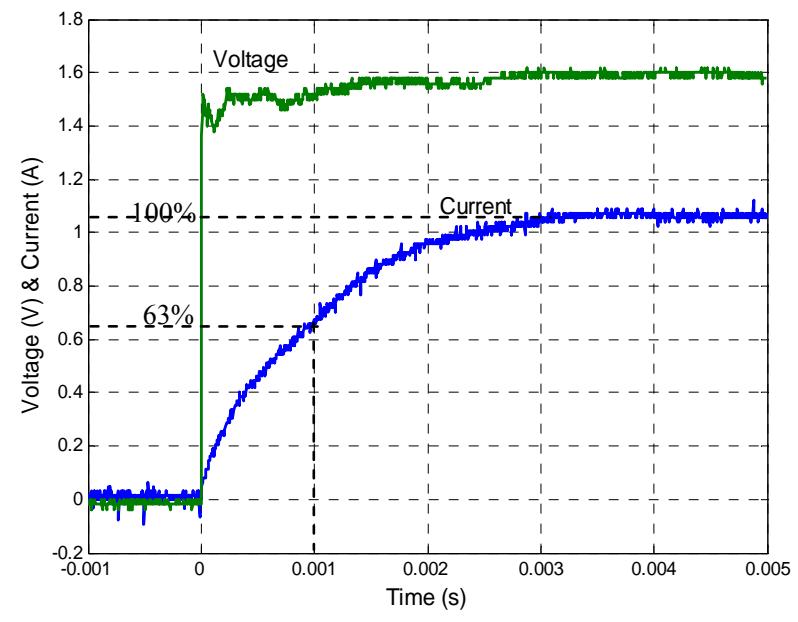

Figure 4. Stalled motor inductance test.

read from Figure 4 when the current reached approximately $63 \%$ of its steady-state value was $1 \mathrm{~ms}$; this yields $\tau=t$. Therefore, the motor inductance was obtained as $L_{a}=\tau R_{t}=1.5 \mathrm{mH}$.

\subsection{Back Electromotive Force Test}

In this test, the throttle plate was manually placed at the fully open position and released. The return spring $K_{s}$ caused rapid return of the throttle plate to its closed position. The rapid closing of the throttle plate, in turn, mechanically drove the dc motor through the reduction gears. As a result, the back emf voltage $e_{b}(t)$ described by

$$
e_{b}(t)=\bar{K}_{b} \omega_{L}(t),
$$

was induced at the motor terminals. Figure 5 shows the back emf voltage and the throttle plate position captured by the oscilloscope during such self-closing of the throttle plate.
Using the angular position data from Figure 5, the throttle plate velocity was calculated by

$\omega_{L}(t)=\mathrm{d} \theta_{L}(t) / \mathrm{d} t$. The resulting angular velocity was plotted together with the angular position and back emf as shown in Figure 6.

The back emf signal was filtered (not shown). Using (10), the back emf constant referred to the load side $\bar{K}_{b}$ $=0.4 \mathrm{~V} \cdot \mathrm{s} / \mathrm{rad}$ was computed at time $t=0.2 \mathrm{~s}$ where the plate angular velocity was the most steady. Since we used the SI unit, it follows that the motor torque constant referred to the load side was $\bar{K}_{m}=\bar{K}_{b}=0.4 \mathrm{~N} \cdot \mathrm{m} / \mathrm{A}$ [24].

The back emf constant of the dc motor $K_{b}$ can be obtained from $K_{b}=\bar{K}_{b} / N=0.0193 \mathrm{~V} \cdot \mathrm{s} / \mathrm{rad}$, where $N=$ 20.68 is the gear ratio. It is important to mention that a different experiment, called a sensorless velocity measurement method, in which the dc motor was detached from the ETC module was performed in Section 3.5.1, and yielded a value $K_{b}=0.0185 \mathrm{~V} \cdot \mathrm{s} / \mathrm{rad}$, which agreed with the value obtained above. The sensorless measure-

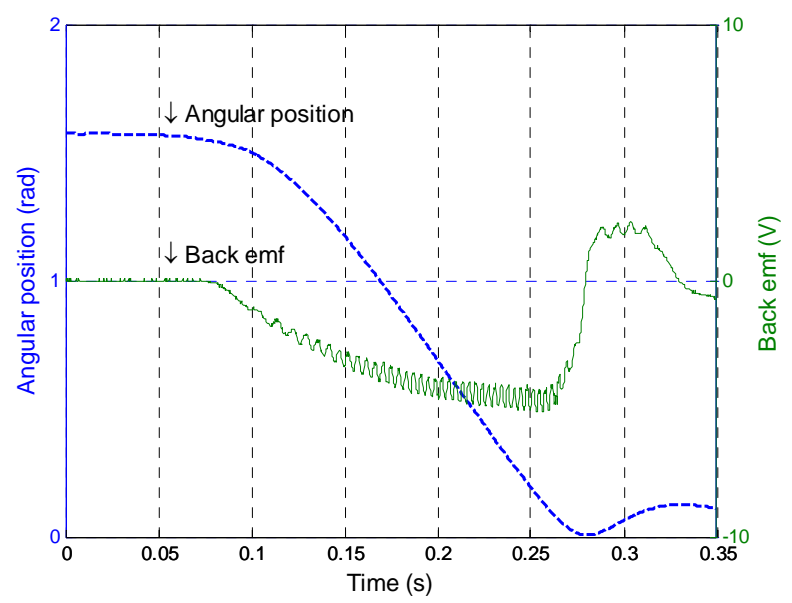

Figure 5. Plot of back emf versus angular position.

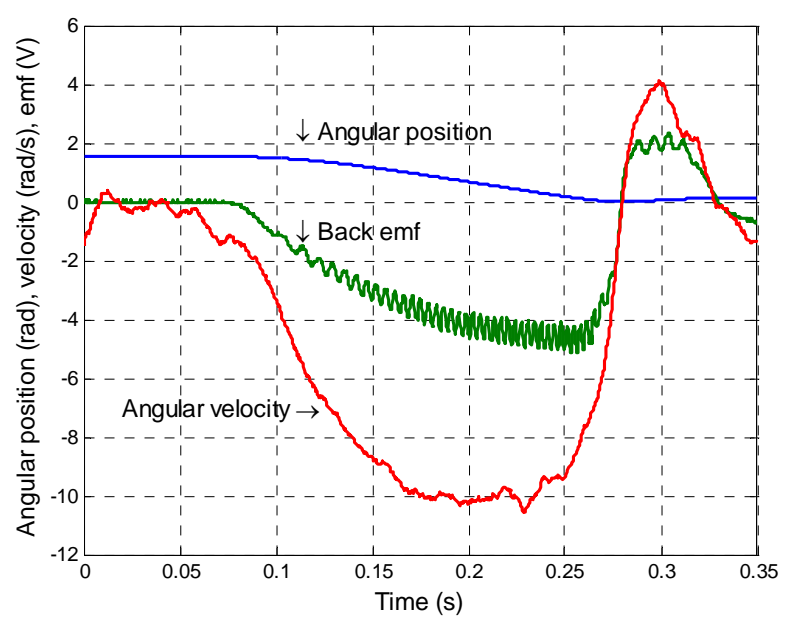

Figure 6. Plot of back emf, angular position and angular velocity. 
ment method is a more reliable method, because, among other things, the fact that the plate angular velocity was judged to be the "most steady" at $t=0.2 \mathrm{~s}$ in Figure 6 was somewhat arbitrary. The new method will be developed in Section 3.5.1.

\subsection{Static Loads Test}

The purpose of static loads test was to identify the friction torque $T_{f}$, the spring pre-loaded torque $T_{P L}$ produced by the return spring, and the return spring constant $K_{s}$. When the throttle plate was moving very slowly, that is, $\omega_{L}(t)=\dot{\omega}_{L}(t) \approx 0$, the torque balance equation is given by, from (6)

$$
T_{L}(t)=K_{s} \theta_{L}(t)+T_{P L}+T_{f} \operatorname{sgn}\left(\omega_{L}\right)=\bar{K}_{m} i_{a}(t) .
$$

In order to measure the parameters in (11), the dc motor was energized by a slowly increasing armature current. This caused a slow rotation of the throttle plate. The armature current and throttle plate angular position were captured by the oscilloscope as shown in Figure 7.

It can clearly be seen from Figure 7 that a larger current was needed (approximately $1.7 \mathrm{~A}$ ) to move the throttle plate towards opening than towards closing (approximately $0.6 \mathrm{~A}$ ). This was because the torque developed by the motor had to overcome the torques produced by the return spring, $K_{s} \theta_{L}(t), T_{P L}$, and the friction torque, $T_{f}$. Using the armature current data together with the motor constant $\bar{K}_{m}=0.4$ obtained from the previous experiment in (11), the load torque equation becomes

$$
T_{L}(t)=K_{s} \theta_{L}(t)+T_{P L} \pm T_{f},
$$

where $\operatorname{sgn}\left(\omega_{L}\right)=1$ during the plate opening, and $\operatorname{sgn}\left(\omega_{L}\right)=-1$ during the plate closing.

Equation (12) can be visualized by the plot of the load torque against the angular position shown in Figure 8. Three approximate straight lines have been inserted. The

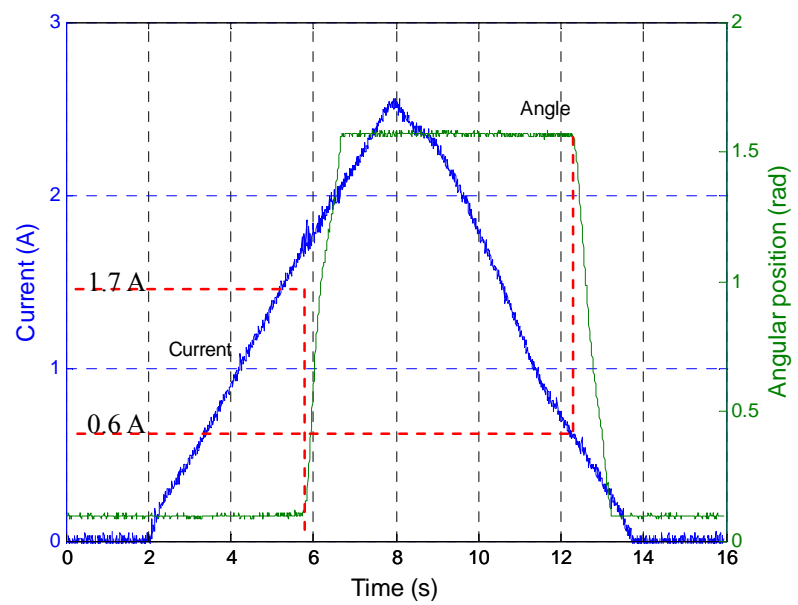

Figure 7. Static loads test.

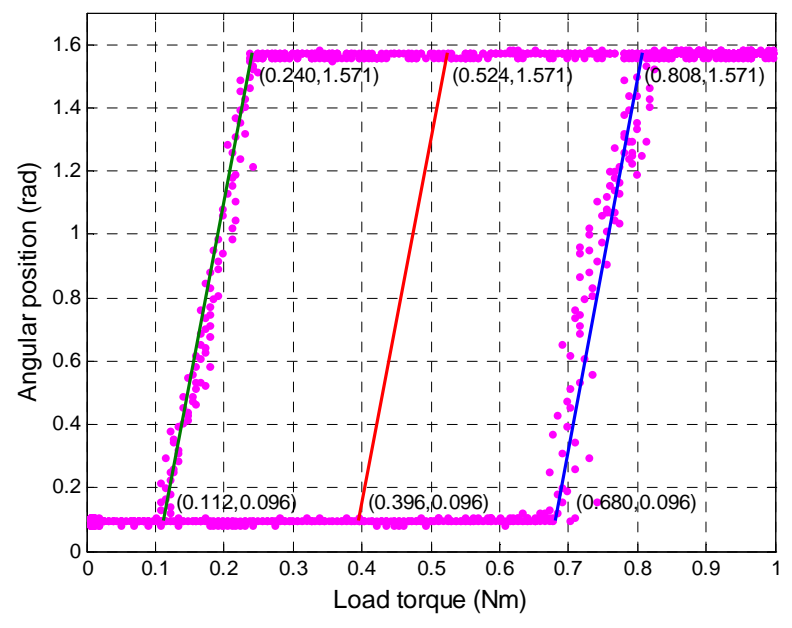

Figure 8. Throttle plate position versus load torque.

middle straight line representing the spring load torque, $K_{s} \theta_{L}(t)+T_{P L}$, lies exactly in the middle between the other two lines. The right straight line represents the torque during the movement towards opening which is the spring load torque plus friction torque,

$K_{s} \theta_{L}(t)+T_{P L}+T_{f}$. The left straight line represents the torque during the plate closing which is the spring load torque minus friction torque, $K_{s} \theta_{L}(t)+T_{P L}-T_{f}$.

The following parameters can be read directly from

Figure 8:

- The spring pre-loaded torque is the minimum torque value on the middle line which reads $T_{P L}=0.396 \mathrm{~N} \cdot \mathrm{m}$;

- The inverse of the slope of the middle line yields the spring constant,

$$
\begin{aligned}
& K_{s}=\Delta T_{L} / \Delta \theta=(0.524-0.396) /(1.571-0.096) \\
& =0.087 \mathrm{~N} \cdot \mathrm{m} / \mathrm{rad} ;
\end{aligned}
$$

- Finally, the friction torque is easily obtained as: $T_{f}=0.680-0.396=0.284 \mathrm{~N} \cdot \mathrm{m} \quad$ (during the movement towards opening), or

$T_{f}=0.524-0.240=0.284 \mathrm{~N} \cdot \mathrm{m} \quad$ (during the movement towards closing).

\subsection{Viscous Frictional Coefficient Test}

The equivalent viscous frictional coefficient $B_{e q}$ of the ETC unit referred to the load side is given by $B_{e q}=N^{2} B_{m}+B_{L}$ (see (6)), where $N=20.68$ is the gear ratio. Since $B_{L}$ comes mostly from the lubricated and sealed throttle shaft joint, it is small and negligible, therefore $B_{e q} \approx N^{2} B_{m}$. Thus we only have to deal with the identification of $B_{m}$. Note that the throttle plate movement is limited to $90^{\circ}$, but the viscous frictional coefficient is associated with the angular velocity and thus requires the dc motor to run freely. The need to run the motor freely can be accomplished by removing the dc motor from the ETC unit. Consider the torque balance 
equation of the detached dc motor

$$
J_{m} \dot{\omega}_{m}(t)+B_{m} \omega_{m}(t)+T_{f m}=T_{m}(t),
$$

where $T_{f m}$ represents static frictional torque of the motor. At any constant speed, $\dot{\omega}_{m}(t)=0$, therefore the frictional torque caused by viscous coefficient $B_{m}$ is given by

$$
T_{m}(t)=B_{m} \omega_{m}(t)+T_{f m} .
$$

It is seen from (14) that if the instantaneous values of $T_{m}(t)$ and $\omega_{m}(t)$ can be captured, the viscous coefficient $B_{m}$ and static frictional torque $T_{f m}$ can be determined.

Since it was desired to obtain the velocity measurement but the detached dc motor was not equipped with any velocity sensor, a 16 pulse-per-revolution optical sensor was attached to the motor shaft, and the detached dc motor was energized to run smoothly. The optical sensor signal, motor voltage and current were recorded by the oscilloscope as shown in Figure 9.

Here, observe that the motor produced 8 ripples per revolution on the voltage and current waveforms caused by the non-uniformity of the magnetic field in the dc motor. This information is useful and can be used to calculate the motor angular velocity from a frequency measurement method proposed below, rather than using the optical sensor method conducted above. This is because the dc motor was small and attaching the optical sensor to the motor shaft was not practically convenient to perform the measurements. The proposed frequency measurement approach may be called a sensorless velocity measurement method and is detailed below.

\subsubsection{Sensorless Velocity Measurement Method}

The optical sensor was disconnected and the motor was mechanically driven by another dc motor with an arbitrary velocity $\omega$, the resulting induced back emf voltage $e_{b}(t)$ shown in Figure 10(a) was recorded.

Two data processing runs were performed on the recorded emf data. The first was filtered to get an average value $\hat{e}_{b}$ (see Table 1); the second was Fast Fourier transformed (FFT) using MATLAB to obtain the associated frequency $f$ (see Table 1). The FFT result is displayed in Figure 10(b). Since there were 8 ripples per revolution on the signals, the back emf constant can be calculated from

$$
K_{b}=\frac{\hat{e}_{b}}{2 \pi(f / 8)}=\frac{4 \hat{e}_{b}}{\pi f} .
$$

The procedures above were repeated with different arbitrary constant velocities and the corresponding $\hat{e}_{b}$ and $K_{b}$ were calculated. Figure 11 shows the result of the FFT, and the calculated data of each test is shown in Table 1.

The overall average $K_{b}$ calculated from Table 1 was $0.0185 \mathrm{~V} \cdot \mathrm{s} / \mathrm{rad}$ which is very close to the result of $K_{b}=$ $0.0193 \mathrm{~V} \cdot \mathrm{s} / \mathrm{rad}$ obtained in Section 3.3 when the dc motor was not removed from the ETC unit. The method of sensorless velocity measurement developed here was judged to be more reliable than the method of Section 3.3, and can be applied to the next parameters identification described in the sequel.

\subsubsection{Identification of Viscous Friction Coefficient}

A series of step input voltages: 2, 4, 6, 8, 10 and $12 \mathrm{~V}$,
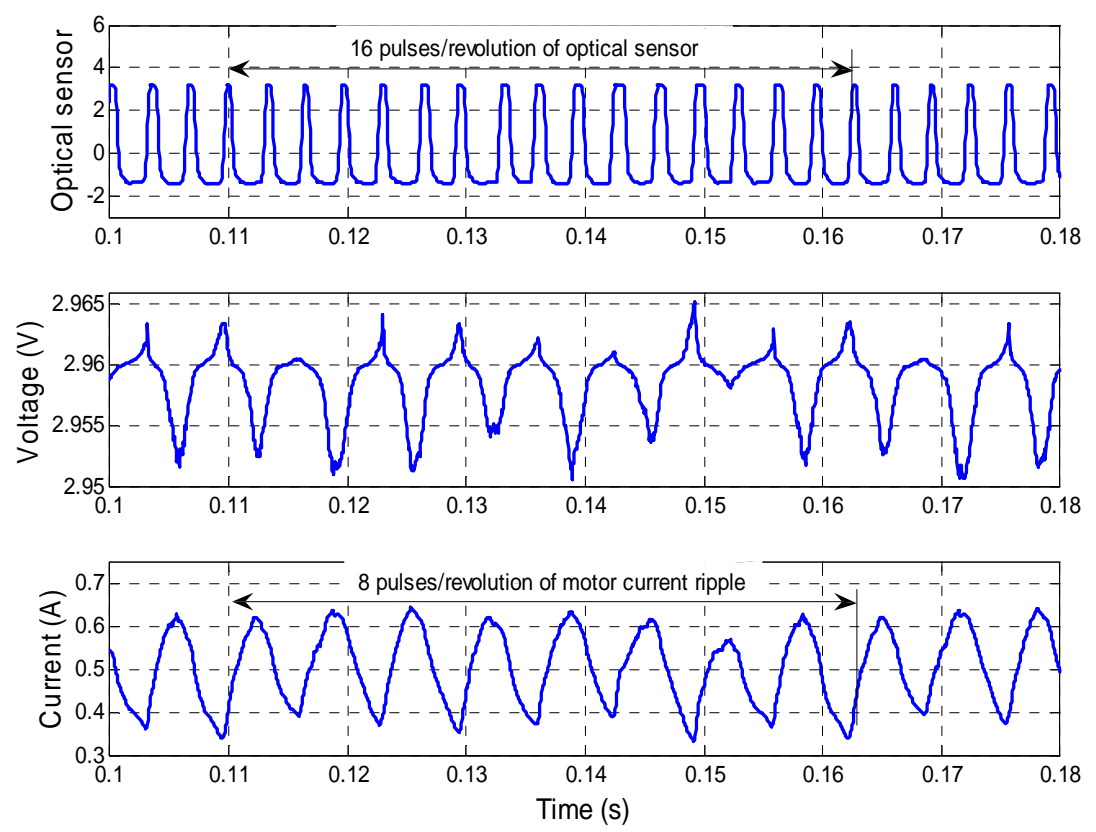

Figure 9. Optical sensor, motor voltage and current signals. 


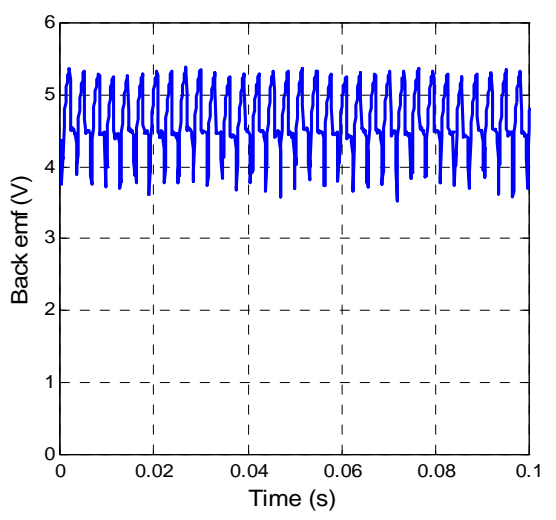

(a)

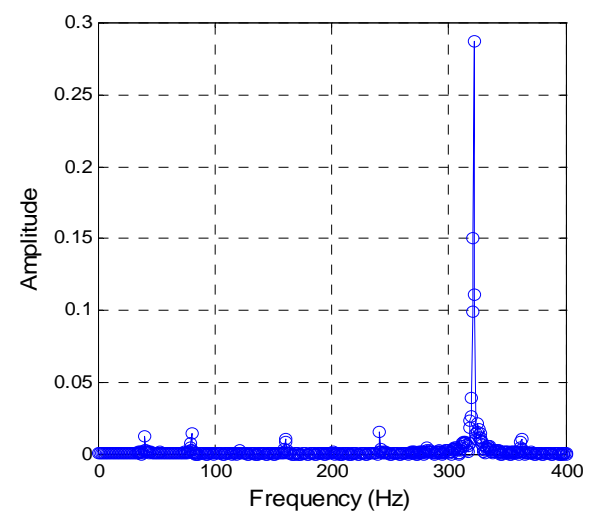

(b)

Figure 10. (a) Back emf voltage, and (b) its associated frequency.
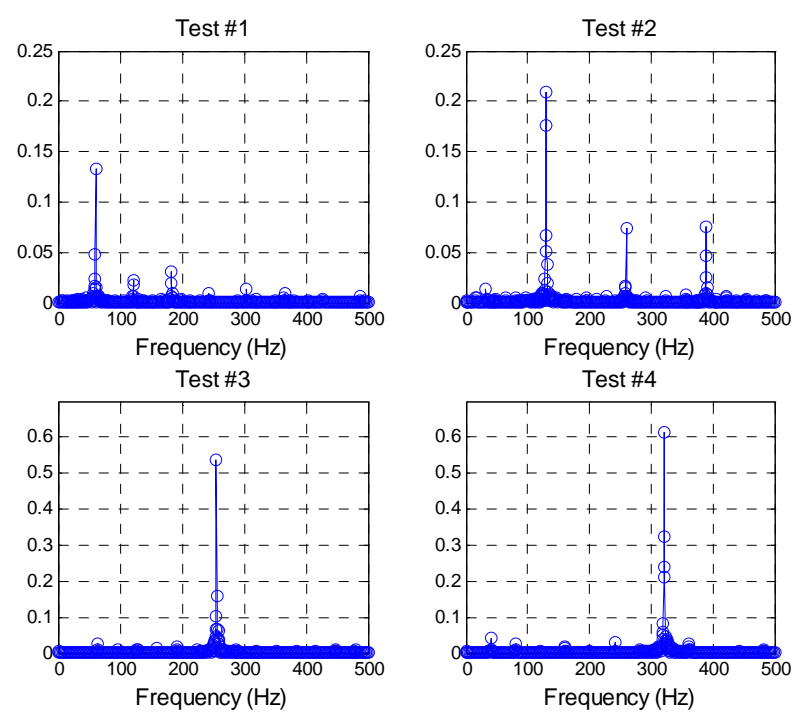

Figure 11. Fast Fourier transform of different motor velocities.

Table 1. Result of sensorless verification test.

\begin{tabular}{cccc}
\hline Test \# & $\begin{array}{c}\text { Average } \\
\text { back emf } \\
\hat{e}_{b}(\mathrm{~V})\end{array}$ & $\begin{array}{c}\text { Frequency } f \\
(\mathrm{~Hz})\end{array}$ & $\begin{array}{c}K_{b}=4 \hat{e}_{b} /(\pi f) \\
(\mathrm{V} \cdot \mathrm{s} / \mathrm{rad})\end{array}$ \\
\hline 1 & 0.8753 & 61.0426 & 0.01827 \\
2 & 1.9009 & 129.41 & 0.018703 \\
3 & 3.7113 & 255.77 & 0.018475 \\
4 & 4.6501 & 321.69 & 0.018405 \\
Average & 2.7844 & 191.9782 & 0.0185 \\
\hline
\end{tabular}

were applied to the armature circuit of the detached dc motor. The voltages and currents were recorded. Figure 12 illustrates the oscilloscope-captured waveforms of the voltage and the current with the $2 \mathrm{~V}$ step input voltage. The responses of the other input voltages were similar but different in amplitudes and therefore were not shown here. For each of the step input voltages, the steady-state
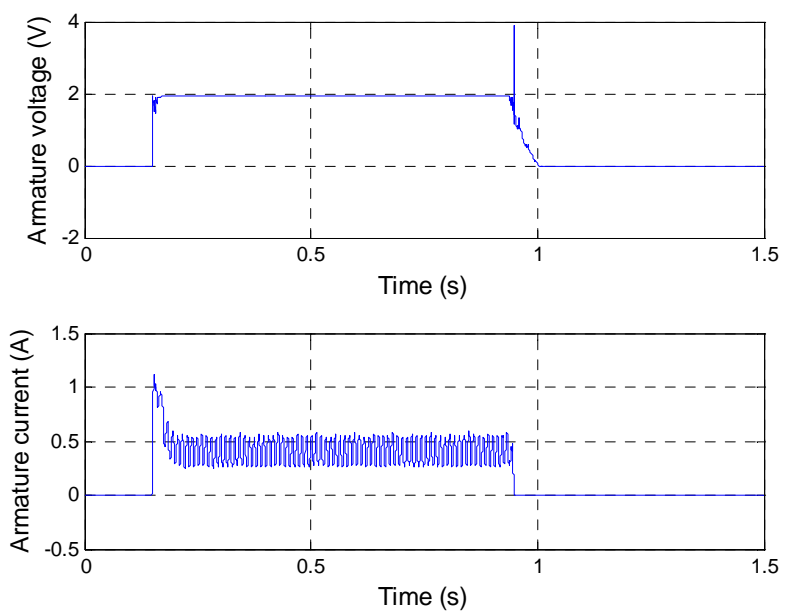

Figure 12. Armature voltage and current responses.

portions of the current data between 0.3 to $0.9 \mathrm{~s}$ were processed by FFT to obtain their associated frequencies $\mathrm{f}$ and the angular velocities were calculated by

$\omega_{m}=2 \pi(f / 8)$. The same portion of the current data, after averaging, were also used to calculate the motor torque from $T_{m}=K_{m} i_{a}$, where $K_{m}=K_{b}=0.0185$. Table 2 reports all data obtained from the experiments and calculations above.

The angular velocity and the motor torque data from Table 2 were plotted and the MATLAB polyfit command was used to perform the best fit of the data. The result is shown in Figure $\mathbf{1 3}$ which is also mathematically represented by (14).

At $\omega_{m}=0$, the approximate static frictional torque of the dc motor read from Figure 13 was $T_{f m}=6.9 \times 10^{-3}$ $\mathrm{Nm}$. The slope of the fitted line was the approximate viscous coefficient of the dc motor: $B_{m}=2.05 \times 10^{-5}$ $\mathrm{Nm}-\mathrm{s} / \mathrm{rad}$. The viscous friction torque generated by the throttle shaft was small and therefore ignored as mentioned earlier in this section. The total viscous friction coefficient referred to the load side was therefore 
Table 2. Result of viscous friction coefficient test.

\begin{tabular}{ccccc}
\hline $\begin{array}{c}\text { Step input } \\
\text { voltage } \\
(\mathrm{V})\end{array}$ & $\begin{array}{c}\text { FFT } \\
\text { Frequency } \\
f(\mathrm{~Hz})\end{array}$ & $\begin{array}{c}\text { Angular } \\
\text { velocity } \\
\omega_{m}(\mathrm{rad} / \mathrm{s})\end{array}$ & $\begin{array}{c}\text { Average } \\
\text { measured } \\
\text { current } i_{a}(\mathrm{~A})\end{array}$ & $\begin{array}{c}\text { Motor } \\
\text { torque } T_{m} \\
(\mathrm{~N} \cdot \mathrm{m})\end{array}$ \\
\hline 2 & 95.2 & 74.80 & 0.405 & 0.0075 \\
4 & 211.2 & 165.90 & 0.576 & 0.0106 \\
6 & 334.6 & 262.76 & 0.688 & 0.0127 \\
8 & 457.9 & 359.61 & 0.813 & 0.0150 \\
10 & 580.0 & 455.51 & 0.903 & 0.0167 \\
12 & 704.5 & 553.33 & 0.934 & 0.0172 \\
\hline
\end{tabular}
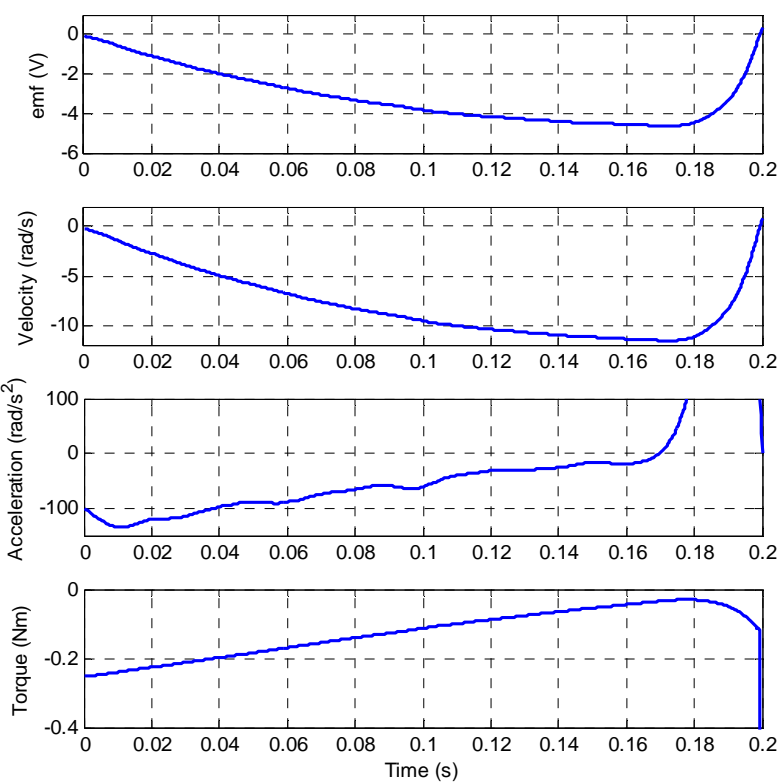

Figure 13. Plot of torques versus angular velocities based on data from Table 2.

$$
\begin{aligned}
B_{e q} & =N^{2} B_{m}=(20.68)^{2} \times 2.05 \times 10^{-5} \\
& =0.0088 \mathrm{~N} \cdot \mathrm{m} \cdot \mathrm{s} / \mathrm{rad} .
\end{aligned}
$$

\subsection{Moment of Inertia Test}

In this test, the dc motor was put back into the ETC unit and the throttle plate was manually released from the fully open position similar to the test in Section 3.3. Since the armature current was zero, the torque balance equation can be described by

$$
T_{\text {tot }}(t)=J_{e q} \dot{\omega}_{L}(t)=-B_{e q} \omega_{L}(t)-K_{s} \theta_{L}(t)-T_{P L}-T_{f}
$$

The back emf data $e_{b}(t)$ and the angular position $\theta_{L}(t)$ were captured during the rapid self closing of the throttle plate. The angular velocity and angular acceleration were calculated from $\omega_{L}(t)=e_{b}(t) / \bar{K}_{b}$, and $\dot{\omega}_{L}(t)=\mathrm{d} \omega_{L} / \mathrm{d} t$, respectively. The total torque $T_{\text {tot }}(t)$ can be calculated from the right hand side of (16). Figure
14 shows these measured and calculated values as a function of time.

Finally, the moment of inertia can be calculated from (16), $J_{e q}=T_{\text {tot }}(t) / \dot{\omega}_{L}(t)$. The calculated average moment of inertia at the time interval of 0.04 to $0.08 \mathrm{~s}$ was $J_{e q}=2.1 \times 10^{-3} \mathrm{~kg} \cdot \mathrm{m}^{2}$. This value was the total moment of inertia of the whole ETC unit. At this point, we have identified all the unknown ETC system parameters and constants. The results are summarized in Table 3.

\section{Parameters Verification}

The main objective of this section is to use the mathematical model described by (2) and (6) to verify the parameters identified in Table 3. Two methods were employed: SIMULINK simulation, and actual real-time control implementation of the ETC system using an XPC TargetBox. The XPC TargetBox is a real-time rapid prototyping device, which is widely used in both industries

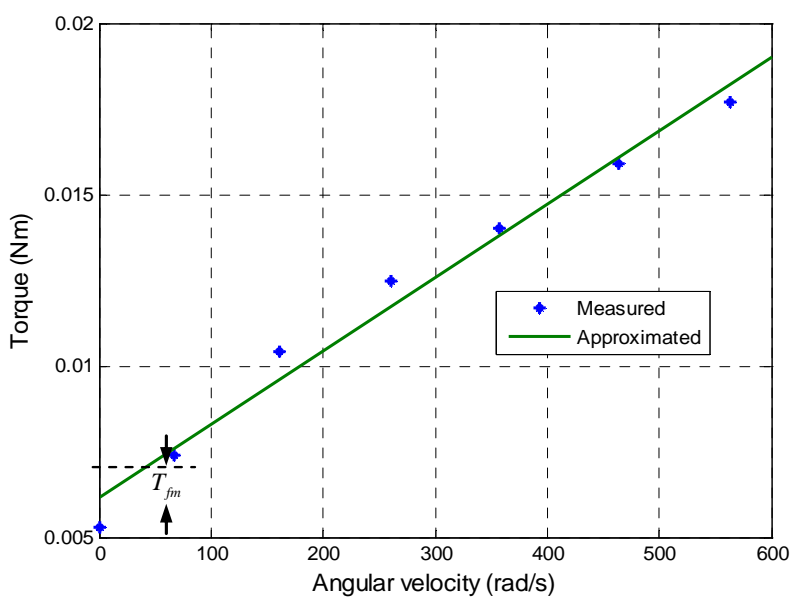

Figure 14. Filtered back emf, velocity, acceleration and torque versus time.

Table 3. Results of ETC parameter identification.

\begin{tabular}{ccc}
\hline Parameters and constants & Symbols & Identified values \\
\hline $\begin{array}{c}\text { Armature resistance } \\
\text { Armature measurement } \\
\text { circuit resistance }\end{array}$ & $R_{a}(\Omega)$ & 1.15 \\
Armature inductance & $R_{t}(\Omega)$ & 1.5 \\
Back emf constant (load side) & $\bar{K}_{a}(\mathrm{mH})$ & 1.5 \\
Motor torque constant (load side) & $\bar{K}_{m}(\mathrm{~N} \cdot \mathrm{m} / \mathrm{Ad})$ & 0.383 \\
Spring constant & $K_{s}(\mathrm{~N} \cdot \mathrm{m} / \mathrm{rad})$ & 0.383 \\
Spring pre-loaded torque & $T_{P L}(\mathrm{~N} \cdot \mathrm{m})$ & 0.087 \\
Friction torque & $T_{f}(\mathrm{~N} \cdot \mathrm{m})$ & 0.284 \\
Equivalent viscous damping & $B_{e q}(\mathrm{~N} \cdot \mathrm{m} \cdot \mathrm{s} / \mathrm{rad})$ & 0.0088 \\
Equivalent moment of inertia & $J_{e q}\left(\mathrm{~kg} \cdot \mathrm{m}^{2}\right)$ & 0.0021 \\
\hline
\end{tabular}


and academia for control analysis and synthesis, see for example $[25,26]$. The SIMULINK diagram is as shown in Figure 15, while the actual control experimental setup is as shown in Figure 16. A PID controller with the gains $K_{p}=9, K_{i}=6$ and $K_{d}=0.1$ was designed to meet the following performance criteria: 1) step response of the throttle plate angular position with no overshoot and steady-state error, and 2) settling time $t_{s} \leq 100 \mathrm{~ms}$.

Figure 17 shows the SIMULINK response of the angular position $\theta_{L}(t)$ with a reference input $r(t)=1$ $\mathrm{rad}$, together with the result captured by the xPC Target scope in real time. It can be seen that the SIMULINK and the real-time control results were practically identical and the performance criteria were satisfied with no overshoot and $t_{s} \leq 100 \mathrm{~ms}$. Hence the parameters obtained in Table 3 were validated. These parameters together with the mathematical model described by (2) and (6) can now be used for other control analysis and synthesis for this particular ETC system.

\section{Design of Model-Based Nonlinear Control Systems}

In this section, we applied the input-output feedback linearization technique [27-29] to design a nonlinear controller for the ETC system. For ease of analysis and reference, we define the following constants in the ETC system described by (2) and (6):

$$
\left.\begin{array}{c}
k_{1}=\frac{K_{s}}{J_{e q}}, \quad k_{2}=\frac{B_{e q}}{J_{e q}}, \quad k_{3}=\frac{\bar{K}_{m}}{J_{e q}}, \quad k_{4}=\frac{T_{f}}{J_{e q}}, \\
k_{5}=\frac{T_{P L}}{J_{e q}}, \quad k_{6}=\frac{\bar{K}_{b}}{L_{a}}, \quad k_{7}=\frac{R_{a}}{L_{a}}, \quad k_{8}=\frac{1}{L_{a}},
\end{array}\right\}
$$

The resulting model can be expressed in a control-affine single-input single-output (SISO) nonlinear state-space form as

$$
\underbrace{\left[\begin{array}{c}
\dot{x}_{1} \\
\dot{x}_{2} \\
\dot{x}_{3}
\end{array}\right]}_{\dot{\boldsymbol{x}}}=\underbrace{\left[\begin{array}{c}
x_{2} \\
-k_{1} x_{1}-k_{2} x_{2}+k_{3} x_{3}-k_{4} S\left(x_{2}\right)-k_{5} \\
-k_{6} x_{2}-k_{7} x_{3}
\end{array}\right]}_{f(\boldsymbol{x})}+\underbrace{\left[\begin{array}{c}
0 \\
0 \\
k_{8}
\end{array}\right]}_{g(\boldsymbol{x})} u,
$$

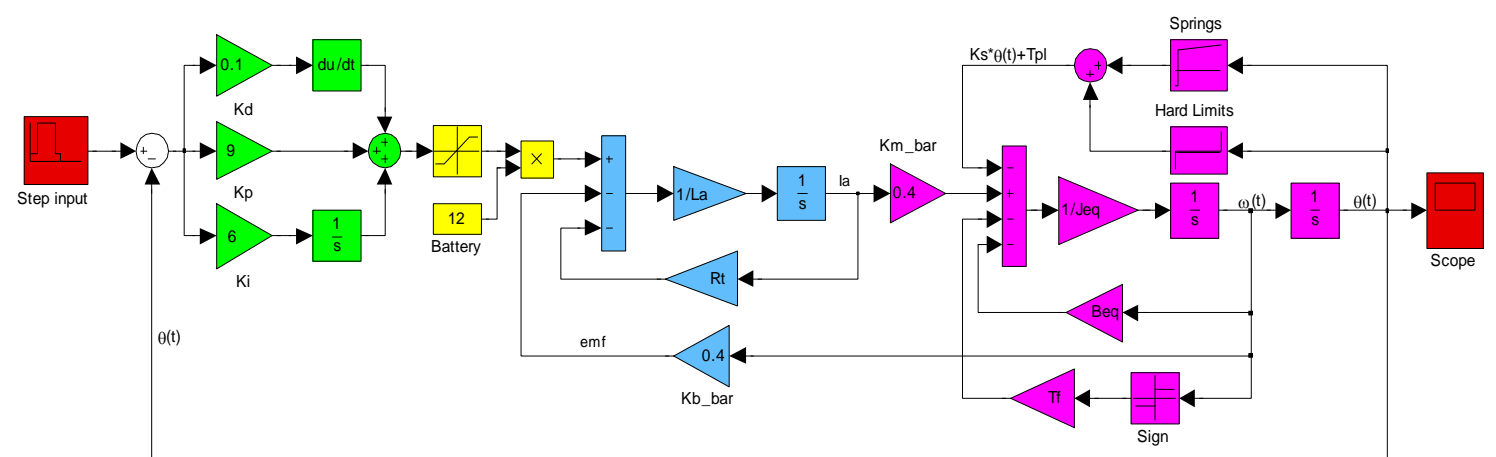

Figure 15. ETC SIMULINK model with PID controller.

$$
y=h(\boldsymbol{x})=x_{1} .
$$

where $x_{1}(t), x_{2}(t)$ represent the angular position and the angular velocity of the throttle plate, respectively, $x_{3}(t)$ is the armature current of the dc motor; $u(t)$ is the armature voltage applied to the dc motor. The function $S\left(x_{2}\right)$ defined by

$$
S\left(x_{2}\right)=\frac{2}{1+\mathrm{e}^{-\delta x_{2}}}-1
$$

is a smooth approximation of the signum function $\operatorname{sgn}\left(x_{2}\right)$ with a small positive number $\delta$ [30]. Figure 18 illustrates the approximated $\operatorname{sgn}\left(x_{2}\right)$ given by $(20)$ with different $\delta$. It is remarked that other signum approximations are also possible, for example, the sigmoid-like function $S\left(x_{2}\right)=x_{2} /\left(\left|x_{2}\right|+\varepsilon\right)$, where $\varepsilon$ is a small positive scalar [31]. However, the approximation function (20) will be used in this study.

Applying the input-output feedback linearization methodology, we obtain

$$
\begin{gathered}
\dot{y}=L_{f} h(\boldsymbol{x})+L_{g} h(\boldsymbol{x}) u=x_{2}, \\
\ddot{y}=L_{f}^{2} h(\boldsymbol{x})+L_{g} L_{f} h(\boldsymbol{x}) u \\
=-k_{1} x_{1}-k_{2} x_{2}+k_{3} x_{3}-k_{4} S\left(x_{2}\right)-k_{5}, \\
\dddot{y}=L_{f}^{3} h(\boldsymbol{x})+L_{g} L_{f}^{2} h(\boldsymbol{x}) u \\
=k_{1} k_{2} x_{1}+\left(-k_{1}+k_{2}^{2}-k_{3} k_{6}\right) x_{2}-k_{3}\left(k_{2}+k_{7}\right) x_{3} \\
+k_{2} k_{5}+k_{2} k_{4} S\left(x_{2}\right)-k_{4} \frac{\mathrm{d} S\left(x_{2}\right)}{\mathrm{d} t}+k_{3} k_{8} u
\end{gathered}
$$

where

$$
L_{f}^{i} h(\boldsymbol{x})=\frac{\partial L_{f}^{i-1} h(\boldsymbol{x})}{\partial \boldsymbol{x}} \boldsymbol{f}(\boldsymbol{x}), L_{g} L_{f}^{i-1} h(\boldsymbol{x})=\frac{\partial L_{f}^{i-1} h(\boldsymbol{x})}{\partial \boldsymbol{x}} \boldsymbol{g}(\boldsymbol{x})
$$

are the Lie derivatives for $i=1,2,3, L_{\boldsymbol{f}}^{o} h(\boldsymbol{x})=h(\boldsymbol{x})$, and $\mathrm{d} S\left(x_{2}\right) / \mathrm{d} t$ is given by

$$
\frac{\mathrm{d} S\left(x_{2}\right)}{\mathrm{d} t}=\frac{2 \delta \mathrm{e}^{-\delta x_{2}}}{\left(1+\mathrm{e}^{-\delta x_{2}}\right)^{2}} \dot{x}_{2} .
$$

Equation (21) shows that the output relative degree is 


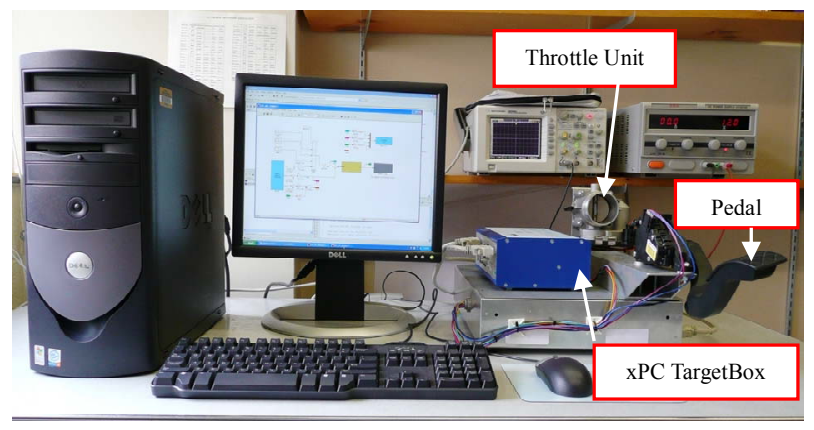

Figure 16. Pictorial view of computer controlled ETC system with xPC Target.

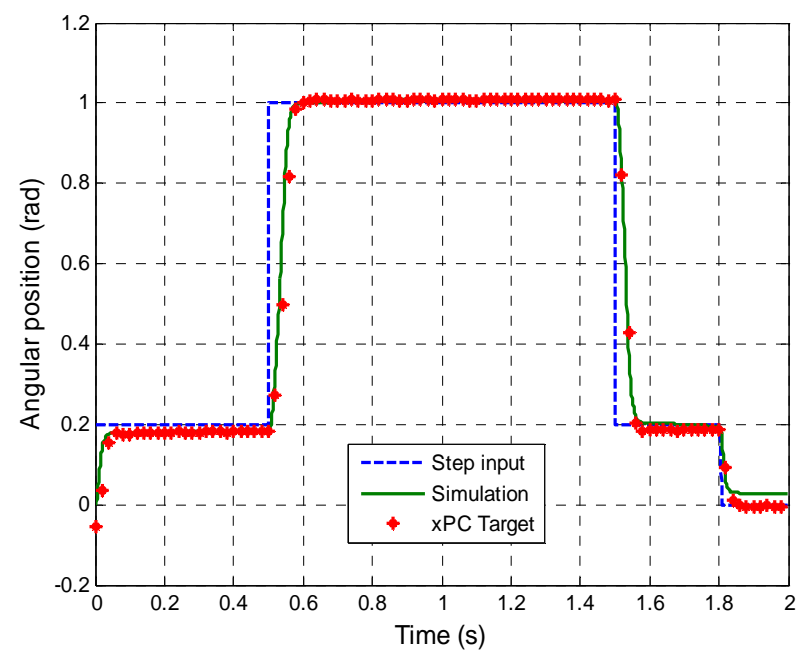

Figure 17. Comparison between real-time control and simulation.

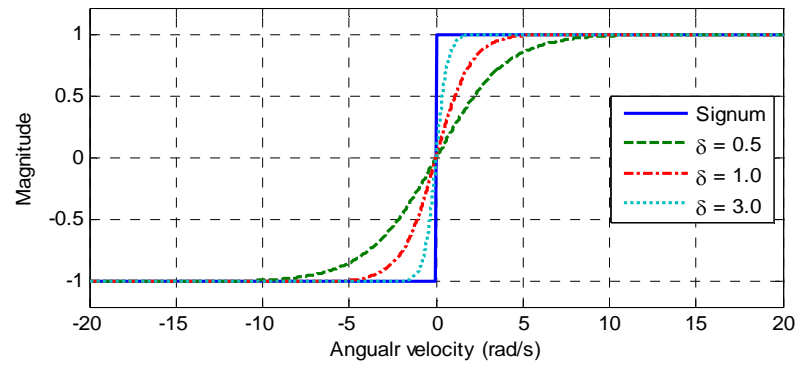

Figure 18. Approximated signum function with different $\delta$.

three and is equal to the dimension of the system. Therefore, the ETC system in (18) and (19) is fully linearizable with the nonlinear transformation given by

$$
\begin{aligned}
\boldsymbol{z} & =\boldsymbol{T}(\boldsymbol{x}) \\
& =\left[\begin{array}{c}
x_{1} \\
x_{2} \\
-k_{1} x_{1}-k_{2} x_{2}+k_{3} x_{3}-k_{4} S\left(x_{2}\right)-k_{5}
\end{array}\right] .
\end{aligned}
$$

It can be shown that the Jacobian matrix associated with (23) has the form

$$
\frac{\partial \boldsymbol{T}(\boldsymbol{x})}{\partial \boldsymbol{x}}=\left[\begin{array}{ccc}
1 & 0 & 0 \\
0 & 1 & 0 \\
-k_{1} & -k_{2}-k_{4}\left(\frac{2 \delta \mathrm{e}^{-\delta x_{2}}}{\left(1+\mathrm{e}^{-\delta x_{2}}\right)^{2}}\right) & k_{3}
\end{array}\right],
$$

which is nonsingular for all $\boldsymbol{x} \in \mathbb{R}^{3}$ and therefore $\boldsymbol{T}(\boldsymbol{x})$ is a global diffeomorphism for (18). Referring to (23), the original nonlinear system in the $x$-coordinates described by (18) and (19) is transformed to a linear system in the $z$-coordinates as

$$
\left.\begin{array}{l}
\dot{z}=A z+B v, \\
y=C z
\end{array}\right\}
$$

where $\boldsymbol{A}, \boldsymbol{B}$ and $\boldsymbol{C}$ are in controllable canonical forms, and $v(t)$ is the transformed input defined by

$$
v=\dddot{y}=b(\boldsymbol{x})+D(\boldsymbol{x}) u,
$$

where $b(\boldsymbol{x})$ is the nonlinear cancellation factor and $D(\boldsymbol{x})$ is a nonsingular scalar function. From (21) and (26), it follows that

$$
\begin{gathered}
b(x)=k_{1} k_{2} x_{1}+\left(-k_{1}+k_{2}^{2}-k_{3} k_{6}\right) x_{2}-k_{3}\left(k_{2}+k_{7}\right) x_{3} \\
+k_{2} k_{5}+k_{2} k_{4} S\left(x_{2}\right)-k_{4} \frac{\mathrm{d} S\left(x_{2}\right)}{\mathrm{d} t}, \\
D(x)=k_{3} k_{8} .
\end{gathered}
$$

In order to achieve output tracking, we introduce the tracking error as $e(t)=y(t)-y_{r}(t)$ where $y_{r}(t)$ is the reference input. The main objective is to force $e(t) \rightarrow 0$ such that $y(t) \rightarrow y_{r}(t)$ as $t \rightarrow \infty$. It follows that

$$
\left.\begin{array}{rl}
\dot{e} & =\dot{y}-\dot{y}_{r}=\dot{z}_{1}-\dot{y}_{r}, \\
\ddot{e} & =\ddot{y}-\ddot{y}_{r}=\dot{z}_{2}-\ddot{y}_{r}, \\
\dddot{e} & =\dddot{y}-\dddot{y}_{r}=\dot{z}_{3}-\dddot{y}_{r}=v-\dddot{y}_{r} .
\end{array}\right\}
$$

A suitable tracking control law for the transformed input $v(t)$ is given by

$$
v=-\boldsymbol{K} \boldsymbol{e}+\dddot{y}_{r}=-\boldsymbol{K}\left[\boldsymbol{T}(\boldsymbol{x})-\boldsymbol{Y}_{r}\right]+\dddot{y}_{r},
$$

where $\boldsymbol{e}=\left[\begin{array}{lll}e & \dot{e} & \ddot{e}\end{array}\right]^{\mathrm{T}}, \boldsymbol{T}(\boldsymbol{x})$ is given in (23), $\boldsymbol{Y}_{r}=\left[\begin{array}{lll}y_{r} & \dot{y}_{r} & \ddot{y}_{r}\end{array}\right]^{\mathrm{T}}$, and the constant feedback gain $\boldsymbol{K} \in R^{1 \times 3}$ is determined such that $\boldsymbol{A}_{c l}=\boldsymbol{A}-\boldsymbol{B} \boldsymbol{K}$ is Hurwitz, that is, all eigenvalues of $\boldsymbol{A}_{c l}$ lie in the open lefthalf complex plane. Finally, the linearizing feedback control law can be obtained from (26) and is given by

$$
u=D^{-1}(\boldsymbol{x})[-b(\boldsymbol{x})+v],
$$

where $v(t)$ is given by (30), and $b(\boldsymbol{x})$ and $D(\boldsymbol{x})$ are given in (27) and (28), respectively. Substituting (31) into (18) 
yields the overall closed-loop nonlinear ETC system in the $x$-coordinates

$$
\left.\begin{array}{l}
\dot{\boldsymbol{x}}=\boldsymbol{f}(\boldsymbol{x})+\boldsymbol{g}(\boldsymbol{x}) D^{-1}(\boldsymbol{x})[-b(\boldsymbol{x})+v], \\
y=h(\boldsymbol{x})=x_{1} .
\end{array}\right\}
$$

\section{Nonlinear Control Simulation Results}

The performance of the controller can be adjusted by carefully designing the control gain matrix $\boldsymbol{K}$ in (30). A pole placement technique will be conducted for this part of the study. As in the PID design of Section 4, we require: 1) the step response of the throttle plate angular position with no overshoot and steady-state error, and 2) a settling time $t_{s} \leq 100 \mathrm{~ms}$. Such a response characteristics can be achieved by placing a pair of complex conjugate poles at $\xi \omega_{n} \pm j \omega_{d}=-70 \pm j 71.41$ with $\omega_{d}=\omega_{n} \sqrt{1-\xi^{2}}$, which correspond to a damping ratio of $\xi=0.7$ and natural frequency of $\omega_{n}=100 \mathrm{rad} / \mathrm{s}$; and a dominating real pole at -35 . These pole locations yield a step response similar to a step response of a first-order system. The resulting gain matrix was

$\boldsymbol{K}=\left[\begin{array}{lll}350 & 14.9 & 0.18\end{array}\right] \times 10^{3}$. The simulation results of the angular position $x_{1}(t)$, the angular velocity $x_{2}(t)$, the armature current $x_{3}(t)$, and the armature voltage or control input $u(t)$ with $\delta=1$ for a series of step reference inputs $y_{r}(t)=r_{o}$, where $r_{o}$ is constant, with different time intervals are as shown in Figure 19. It is
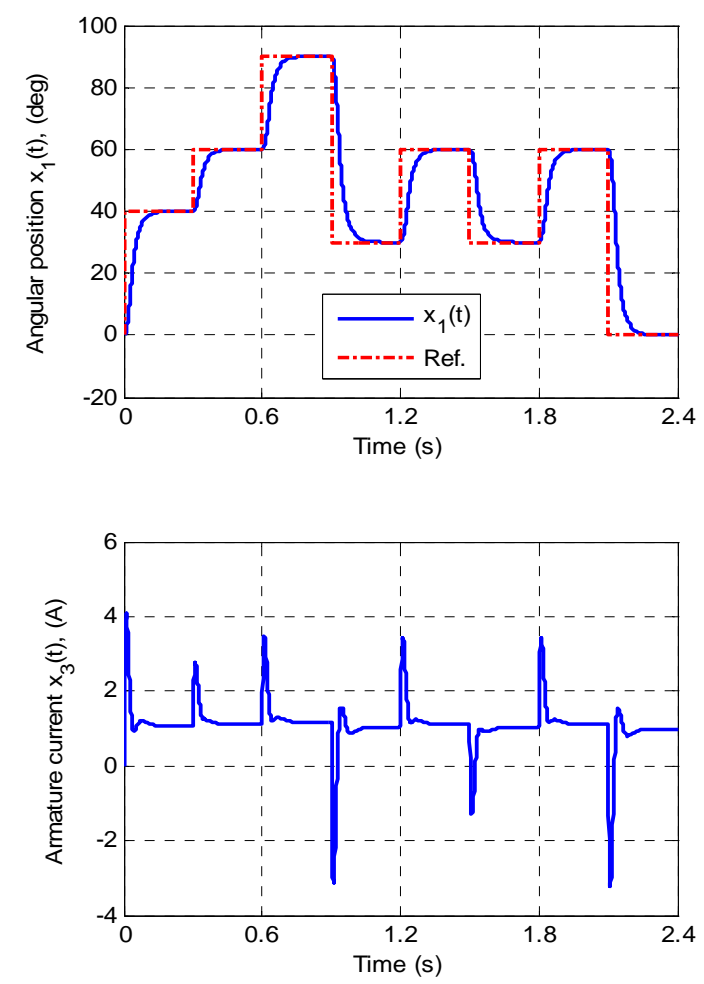

seen that all responses are well within reasonable ranges, especially the unsaturated control input $u(t)$. Figure 20 displays the simulation results for a series of step plus ramp inputs with different time intervals, $y_{r}(t)=r_{o}+r_{1} t$, where $r_{o}$ and $r_{1}$ are constants; and Figure 21 for a sinusoidal input $y_{r}(t)=90 \sin (2 \pi t / 2.4)$.

Simulation results show that the controller yields excellent tracking performance regardless of the types of reference signals. However, the ramp response in Figure 20 exhibits a small overshoot of about 2 degrees as the ramp signal introduces one more dominant pole into the closed-loop system.

\section{Conclusion}

We presented the modeling and unknown system parameters identification of an industrial Bosch automotive ETC system. The identification was based on a series of laboratory experiments, measurements and data processing techniques. The validation of the identified parameters by comparing the simulation results with the real-time implementation using an XPC Target under a PID control scheme produced excellent results for this particular ETC system which demonstrated the effectiveness and reliability of the parameters identification techniques. We then proposed a nonlinear closed-loop control system design based on the input-output linearization approach. The simulation results showed that the nonlinear controller developed was capable of accom-
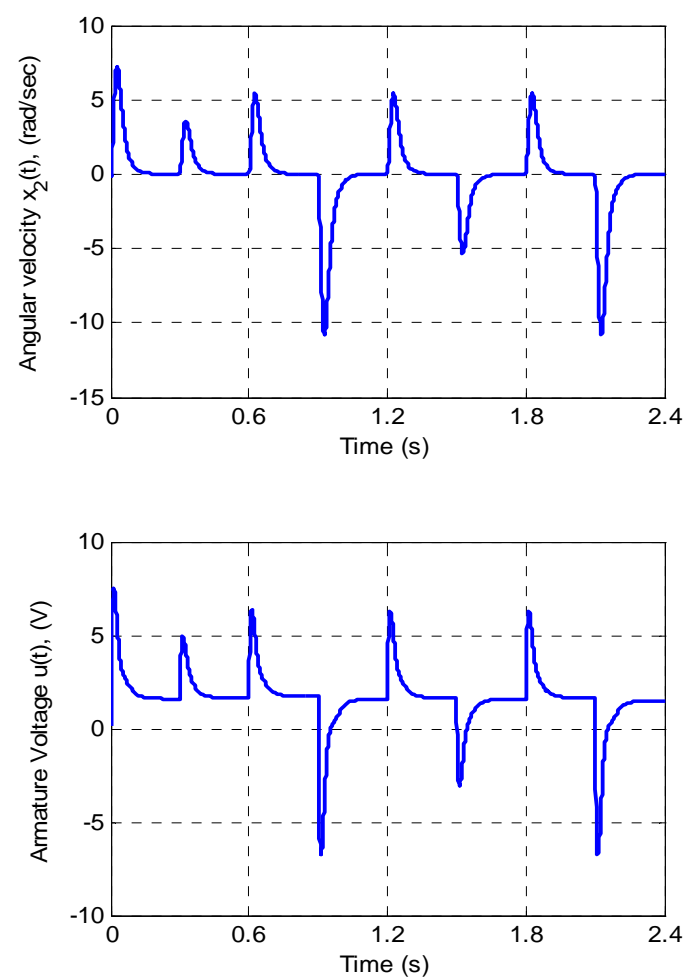

Figure 19. Simulation results of step reference input with different durations. 

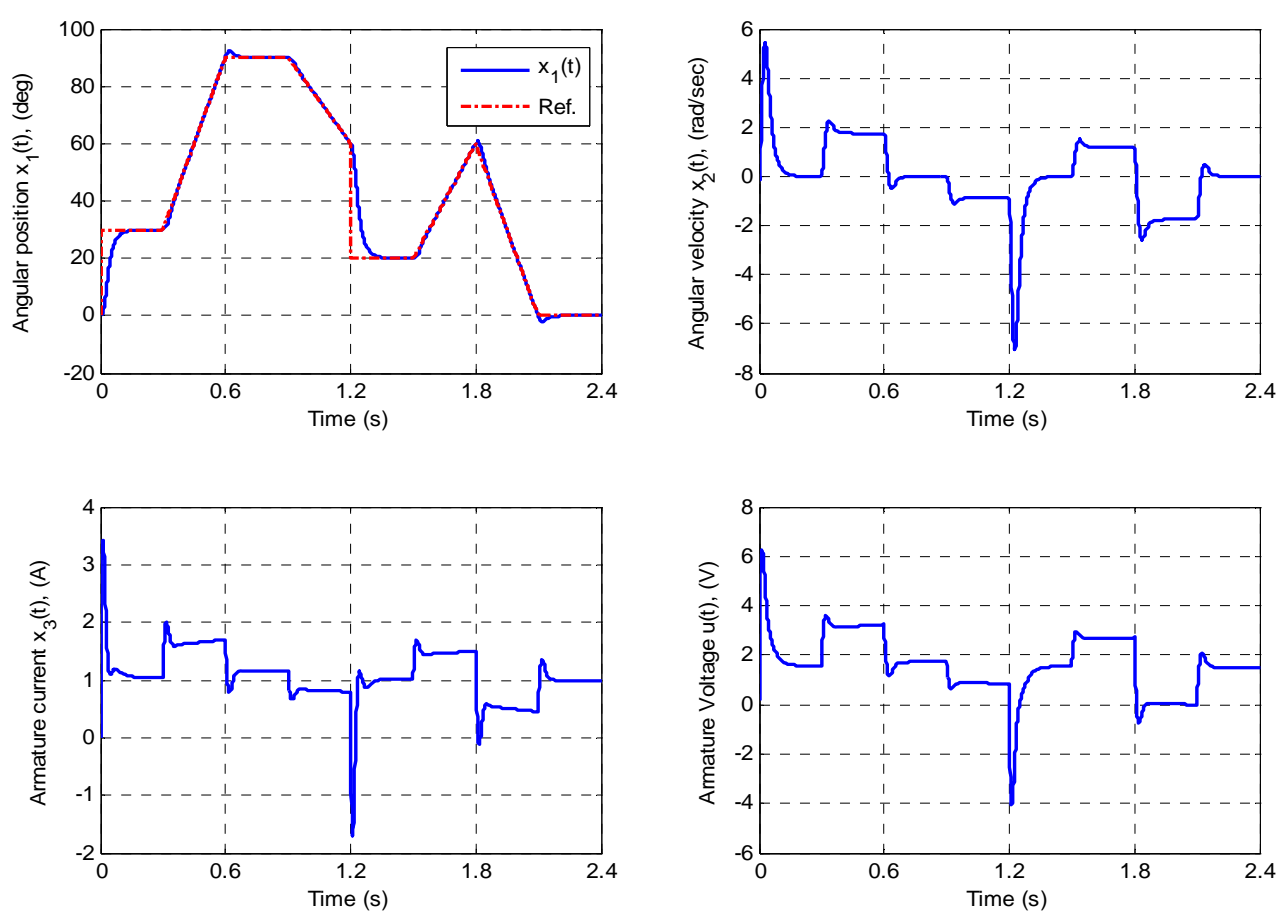

Figure 20. Simulation results of step plus ramp reference input with different durations.
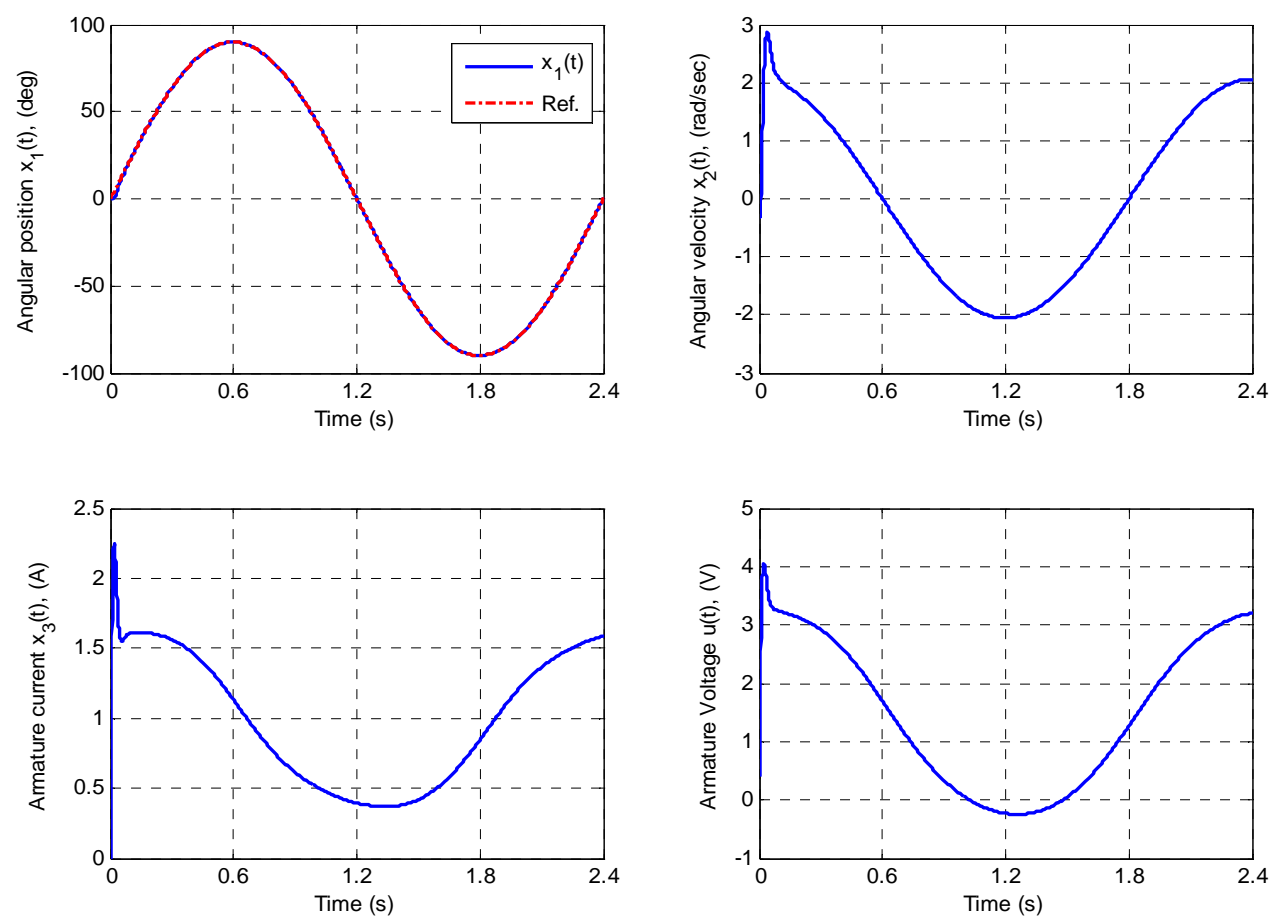

Figure 21. Simulation results of sinusoidal reference input.

plishing the tracking tasks for different types of reference inputs with excellent performance. The results presented in this paper can be considered as an interesting and important case study encompassing system modeling, system parameters identification, nonlinear controller designs, real-time control, and analytical solutions of the closed-loop trajectories of the nonlinear ETC system. The techniques and methodology developed are applicable to similar and/or other types of ETC systems. In view of a recent massive auto recalls due to the controversial uncontrollable engine accelerations, the results of this paper may inspire further research interest on the drive- 
by-wire technology.

\section{REFERENCES}

[1] H. Streib and G. Bischof, "Electronic Throttle Control (ETC): A Cost Effective System for Improved Emissions, Fuel Economy, and Drivability," SAE No. 960338, 1996.

[2] W. Huber, B. Lieberoth-Leden, W. Maisch and A. Reppich, "Electronic Throttle Control," Automotive Engineering, Vol. 99, No. 6, 1991, pp. 15-18.

[3] T. Kowatari, T. Usui, and S. Tokumoto, "Optimization of an Electronic-Throttle-Control Actuator for GasolineDirect-Injection Engines," SAE Paper No. 1999-01-0542, 1999.

[4] C. Rossi, A. Tilli and A. Tonielli, "Robust Control of a Throttle Body for Drive by Wire Operation of Automotive Engines," IEEE Transactions on Control Systems Technology, Vol. 8, No. 6, 2000, pp. 993-1002. doi:10.1109/87.880604

[5] R. N. K. Loh, T. Pornthanomwong, J. S. Pyko, A. Lee and M. N. Karsiti, "Modeling, Parameters Identification, and Control of an Electronic Throttle Control (ETC) System," Proceedings of 2007 International Conference on Intelligent and Advanced Systems, Vol. 1, Malaysia, 2007, pp. 1029-1035. doi:10.1109/ICIAS.2007.4658541

[6] C. C. de Wit, I. Kolmanovsky and J. Sun, "Adaptive Pulse Control of Electronic Throttle," Proceedings of American Control Conference, Virginia, 2001, pp. 28722877.

[7] A. Contreras, I. Quiroz and C. C. de Wit, "Further Results on Modeling and Identification of an Electronic Throttle Body," Proceedings of 10th Mediterranean Conference on Control and Automation, Lisbon, 2002.

[8] J. Deur, D. Pavkovic, N. Peric, M. Jansz and D. Hrovat, "An Electronic Throttle Control Strategy Including Compensation of Friction and Limp-Home Effects," IEEE Transactions on Industry Applications, Vol. 40, No. 3, 2004, pp. 821-833. doi:10.1109/TIA.2004.827441

[9] J. Deur, D. Pavkovic, M. Jansz and N. Peric, "Automatic Tuning of Electronic Throttle Control Strategy," Proceedings of 11th Mediterranean Conference on Control and Automation (MED'03), Rhodes, 2003.

[10] M. Vasak, L. Mladenovic and N. Peric, "Clustering-Based Identification of a Piecewise Affine Electronic Throttle Model," Proceedings of the 31st Annual Conference of IEEE Industrial Electronics Society, Vol. 1, Raleigh, 2005, pp. 177-182.

[11] K. Nakano, U. Sawut, K. Higuchi and Y. Okajima, "Modeling and Observer-Based Sliding-Mode Control of Electronic Throttle Systems," ETCI Transactions on Electrical Engineering, Electronics, and Communications, Vol. 4, No. 1, 2006, pp. 22-28.

[12] C. Yang, "Model-Based Analysis and Tuning of Electronic Throttle Controllers," SAE Paper \#2004-01-0524, 2004.

[13] R. N. K. Loh, S. Elashhab, M. A. Zohdy and A. Lee, "Modeling and Design of an Automotive Throttle Control System," Proceedings of the International Conference on
Intelligent Systems (ICIS2005), Kala Lumpur, December 2005.

[14] A. Kitahara, A. Sato, M. Hoshino, N. Kurihara and S. Shin, "LQG Based Electronic Throttle Control with a Two Degree of Freedom Structure," Proceedings of 35th Conference on Decision and Control, Kobe, 11-13 December 1995, pp. 1785- 1788.

[15] M. Horn and M. Reichhartinger, "Second-Order Sliding Mode Control of Electronic Throttle Valves," International Workshop Variable Structure Systems 2008, Antalya, 2008, pp. 280-284. doi:10.1109/VSS.2008.4570721

[16] U. Ozguner, S. Hong and Y. Pan, "Discrete-Time Sliding Mode Control of Electronic Throttle Valve," Proceedings of 40th IEEE Conference on Decision and Control, Orlando, 4-7 December 2001, pp. 1819-1824.

[17] M. Baric, I. Petrovic and N. Peric, "Neural NetworkBased Sliding Mode Control of Electronic Throttle," Engineering Applications of Artificial Intelligence, Vol. 18, 2005, pp. 951-961. doi:10.1016/i.engappai.2005.03.008

[18] Z. Xu and P. Ioannou, "Adaptive Throttle Control for Speed Tracking," California PATH Research Paper, UCB-ITS-PRR-94-09, April 1994.

[19] D. Kim, H. Peng, S. Bai and J. M. Maguire, "Control of Integrated Powertrain with Electronic Throttle and Automatic Transmission," IEEE Transactions on Control Systems Technology, Vol. 15, No. 3, 2007, pp. 474-482. doi:10.1109/TCST.2007.894641

[20] T. Aono and T. Kowatari, "Throttle-Control Algorithm for Improving Engine Response Based on Air-Intake Model and Throttle-Response Model," IEEE Transactions on Industrial Electronics, Vol. 53, No. 3, 2006, pp. 915-921. doi:10.1109/TIE.2006.874263

[21] "Technical Customer Information Manual: DV-E5 Throttle Body for ETC Systems," Robert Bosch GmbH, 2000.

[22] L. Ljung, "System Identification: Theory for the User," Prentice Hall, Upper Saddle River, 1987.

[23] T. Soderstrom and P. Stoica, "System Identification," Prentice Hall, Upper Saddle River, 1989.

[24] B. C. Kuo, "Automatic Control Systems," 8th Edition, Prentice Hall, Upper Saddle River, 2003.

[25] P. S. Shiakolas and D. Piyabongkarn, "Development of a Real-Time Digital Control System with a Hardwarein-the-Loop Magnetic Levitation Device for Reinforcement of Controls Education," IEEE Transactions on Education, Vol. 46, No. 1, 2003, pp. 79-87. doi:10.1109/TE.2002.808268

[26] K. H. Low, H. Wang and M. Y. Wang, "On the Development of a Real Time Control System by Using xPC Target: Solution to Robotic System Control," Proceedings of the 2005 IEEE International Conference on Automation Science and Engineering, Edmonton, 2005, pp. 345-350.

[27] A. Isidori, "Nonlinear Control Systems," Springer-Verlag, New York, 1995. doi:10.1007/978-1-84628-615-5

[28] H. K. Khalil, "Nonlinear Systems, " 3rd Edition, Prentice Hall, Upper Saddle River, 2002.

[29] H. Marquez, "Nonlinear Control Systems, Analysis and 
Design," Wiley Interscience, Hoboken, 2003.

[30] H. A. Talebi, R. V. Patel and K. Khorasani, "Control of Flexible-Link Manipulators Using neural Networks," Lecture Notes in Control and Information Sciences,
Springer-Verlag, London, 2001.

[31] C. Edwards and S. Spurgeon, "Sliding Mode Control Theory and Applicationsm" Taylor \& Francis, London, 1998. 